\title{
Jiming WANG \\ Theoretical research and application of petrochemical Cyber-physical Systems
}

(C) The Author(s) 2017. Published by Higher Education Press. This is an open access article under the CC BY license (http:// creativecommons.org/licenses/by/4.0)

\begin{abstract}
A petrochemical smart factory is a green, efficient, safe and sustainable modern factory that combines cutting-edge information and communication technology with petrochemical advanced technology and equipment. A Cyber-physical System (CPS) is the infrastructure of a petrochemical smart factory. Based on the future challenges of the petrochemical industry, this paper proposes the definition, connotation and framework of a petrochemical CPS and constructs a CPS system at the enterprise, unit and field levels, respectively. Furthermore, the paper provides theoretical support and implementation reference of a CPS in the petrochemical industry and other industries by investigating the construction practice of a multi-level CPS in the China Petrochemical Corporation (SINOPEC).
\end{abstract}

Keywords Cyber-physical System (CPS), petrochemical industry, smart factory

\section{Introduction}

The development of global informatization is entering a new stage. After the rapid development of digitalization and networks, intelligence is becoming one of the most important features of global informatization to high-end development (Zhou, 2017; Kim and Chilamkurti, 2016), increasingly penetrating into the processes of product development, design, and manufacturing, and promoting major changes in production process. At present, intelligent manufacturing, which is characterized by the fusion of information communication technology and the manufacturing industry, has become the main trend of global

Received June 26, 2017; accepted July 31, 2017

Jiming WANG (₫)

China Petrochemical Corporation, SINOPEC, Beijing 100728, China

E-mail: liujun@sinopec.com manufacturing development (Chen, 2017; Rymaszewska et al., 2017) and the crucial means by which the world's major industrial countries cope with changes in global industrial competition in the future. To achieve this fusion, the core is CPS which connects the physical world and virtual network information (Wen et al., 2012; Li, 2016b; Ashibani and Mahmoud, 2017; Lee and Shin, 2017; Poudel et al., 2017).

In 2006, the National Science Foundation (NSF) first presented a CPS that received increased attention by academia and industry. The current definition of CPS has not yet been unified (Wang and Xie, 2011). In terms of industry, CPS is an "intelligent closed-loop network system" composed of embedded systems, network, software, data platforms and other information elements and production equipment, sensing devices, operators and other physical entities. Its essence is to use advanced sensing, communication, computing and control technology to achieve a high degree of integration and interaction of information units and physical entities in the network environment as well as build a bottom-up information flow from data-sensing to data processing and top-down control flows from analytics to precision execution, ultimately achieving the intelligent manufacturing goals of selfcoordination, efficiency promotion, performance optimization and security assurance (Liu et al., 2016).

In the present environment, where China vigorously promotes the integration of information technology and industrialization (Ministry of Industry and Information Technology of the People's Republic of China et al., 2011; Miao, 2015) as well as intelligent manufacturing (The State Council of the People's Republic of China, 2015) to achieve industrial restructuring and upgrading (Jiang, 2003; Hu, 2012), Sinopec took the lead in the research and exploration of petrochemical CPS in 2013 (Li, 2016a; Li et al., 2015), focusing on three main lines-whole process integrated production control, whole process integration optimization and life cycle integrated asset management - to create a robust and dynamic factory 
operation and management. The first batch of four pilot smart factory enterprises has achieved the integration of information, communication and the physical world after years of digital, network, and intelligent construction, which promoted enterprises to achieve safe, environmentally friendly, stable and efficient production organization and operation control.

Based on the characteristics and development trends of the petrochemical industry, this paper analyzes the key issues of petrochemical CPS and proposes the definition and connotation of the petrochemical CPS. Based on the practice of the Sinopec smart factory, this paper shows the application pattern and concrete scenarios of petrochemical CPS in petrochemical smart factories.

\section{Research progress of industrial CPS}

In 2013, Germany's "Recommendations for Implementing Industrie 4.0" highlighted CPS as the core technology of Industry 4.0 (The Essence of Industry 4.0, 2015; Jiang et al., 2012; Lu, 2016), outlined the advantages of CPS in manufacturing and embedded domains (The Essence of Industry 4.0, 2015; Kagermann et al., 2013; Zezulka et al., 2016), proposed the construction of "new CPS platforms based on service and real-time supporting" and made a series of strategic deployments in standard-setting, technology research and development, and verification-testplatform construction. This quickly set off the CPS in the field of industrial research and application. Prior to CPS, China had conducted similar research, which is closely linked to the government's policies in the industrial sector. In 2016, China proposed the requirements of deepening the integration of manufacturing and the Internet (The State Council of the People's Republic of China, 2016) and made further requirements on the future development of CPS in the section "strengthen infrastructure support of fusion development." The policy continuation and support led China's CPS development into the fast lane. The research progress of China's industrial CPS is mainly reflected in the following three aspects.

(1) China's "White Paper on Cyber-physical System (2017)" was released (Cyber-physical Systems development forum of China, 2017). The white paper revolves around the connotation, realization, construction and application of CPS and discusses the "overall positioning" through the deep excavation of CPS connotation and extension; CPS is a set of integrated technology systems that support the integration of two depths, with the goal of achieving the "optimal allocation of resources" by opening up four processes (state perception, real-time analysis, scientific decision-making, precise execution) of two spaces (information space and physical space) in a closed-loop automatic data flow. Perception and automatic control, industrial software, industrial networks, and industrial cloud and intelligent service platforms are known as the "new four base", which are also the four core technical elements of CPS. In the process of data closed-loop automatic flow, six typical features (datadriven, software definition, ubiquitous connection, virtual reality mapping, heterogeneous integration, system autonomy) are presented, which are applied to three levels (unit level, system level, systems' system level) of CPS (Cyberphysical Systems development forum of China, 2017).

(2) Research progress of CPS in Chinese Academia and Industry. Hu et al. (2016) performed a systematic study of the characteristics, inherent laws and development trends of intelligent technology innovation and new industrial revolution, which is featured by cutting-edge phenomena such as intelligent manufacturing, Industry 4.0, artificial intelligence, virtual reality, Internet + , Internet of Things, CPS, big data, cognitive technology, etc. They also proposed the "three-body intelligence model," which consists of physical entities, awareness of the human body and digital imaginary, and stated that the two-body digital, two-body recognition, three-body interconnection were the most important prelude and trend of human society to intelligence. Intelligence is the core and origin of intelligent manufacturing, and CPS is a form of intelligent implementation. CPS can precisely control and intelligently drive physical entities such as devices and improve the artificial intelligence of man-made technology systems by state perception, analysis and calculation, self-decision making, precision execution, and learning promotion. The so-called artificial intelligence is an ability to imitate and extend beyond human intelligence. It has cognitive ability, analytical decision-making ability, learning ability, and even the ability to create knowledge (Ning, 2016; Zhao, 2016).

(3) Application of CPS in various industries. China has conducted extensive CPS research in major industrial sectors such as electricity (Li, 2016b; Poudel et al., 2017; Zhao et al., 2011; Zhao et al., 2010), aerospace (Hou et al., 2014), automobiles (Xu et al., 2017; Xu et al., 2014), and health/medical (Jezewski et al., 2016). In particular, there are many research achievements on CPS in the power industry (Li et al., 2017a). For example, power grid CPS (GCPS) emphasizes the deep integration of information flow, control flow and energy flow in cyberspace and physical space, and regards the cross-security problem of information network and grid network in the process of integration as the core problem in this field. In view of the GCPS security threat ( $\mathrm{Li}$ et al., 2017a), research on network theory, fault propagation model and analysis method has been carried out. Information space and physical space collaborative defense are achieved through the establishment of coordination mechanisms between different means of coordination. A corresponding study was also performed on the GCPS software credibility and information security (Liang et al., 2015).

In addition, since the Chinese petrochemical industry is facing many serious challenges, such as slowing-down and 
overcapacity of market growth as well as increasing constraints on security and environment, this paper performs CPS application research in the process of promoting the construction of petrochemical smart plants, which is regarded as an important starting point of quality improvement, transformation and upgrading.

\section{Challenges of petrochemical CPS}

With the rapid development of information and communication technology, such as the Internet, cloud computing, large data, and the Internet of Things, the petrochemical industry has accelerated its integration with information technology and has entered an intelligent stage. New environments and new technology greatly strengthen the driving force of petrochemical industry intelligent construction, and the change characterized by innovations is further deepening, as mainly reflected in four aspects, including the value chain, the production and service model, the control chain, and raw materials and the energy environment ( $\mathrm{Li}, 2016 \mathrm{a})$.

(1) Change of value chain

At the energy supply side, clean energy has achieved an alternative to fossil fuels to some extent, pushing the extension of the petrochemical value chain. At present, in China, the proportion of hydropower, nuclear power, solar energy and other non-fossil energy in primary energy continues to improve. The ratio in 2016 is approximately $13.3 \%$, and it is expected to reach $15 \%$ in 2020 and $20 \%$ in 2030 (Gao and Kang, 2017). The concept of the "energy Internet" has been proposed and applied in the intelligent grid field (Khajenasiri et al., 2017; Zhou et al., 2016). The energy Internet has become a new business mode that will break the value chain with fossil fuel as its core, promote the development and utilization of new energy to the upper reaches, and integrate with fossil energy consumption industries (such as transportation) downstream of the value chain.

(2) Change of production and service model

Petrochemical product technology develops to the special directions of high performance and high added value. Refining chemicals closer to the client, with technology-intensive, high value-added, good economic returns, becomes the direction of transformation and upgrading of the petrochemical industry. In some European countries and Japan, the development of petrochemical industries has been focused on the development of high-performance, high value-added and special chemical production, enhancing product added value. At the same time, a new value-oriented service model began to emerge. From proposing the PSE2 (PSE of Enterprise) (Naraharisetti et al., 2009), cloud manufacturing model (Golightly et al., 2016; Hao and Helo, 2017; Wang et al., 2017) to proposing to integrate small and medium-sized businesses and large groups into new value chain networks in industry 4.0 (Kagermann et al., 2013) and SMLC (Smart Process Manufacturing Engineering Virtual Organization Steering Committee, 2009), this initiative forms a new integration model of the petrochemical industry, the Internet of things, and service.

(3) Uncertainty of management and control chain

The change of value chain and service model of the petrochemical industry will lead to the increase of uncertainties in petrochemical management and control processes. In the supply side of raw materials, petrochemical production needs to adapt to the diversification of raw material sources. In the production link, the deterioration of raw materials, the upgrading of the quality of oil products, and the variety and small batch production of high value-added products have increased the uncertainty of management and control of production processes. In the sales link, the change of payment methods and customer demand models needs to explore the development of newgeneration e-business modes.

(4) Diversification of raw materials and energy environment constraints

The petrochemical industry pays great attention to the development of the green low-carbon and circular economy, and it is gradually shifting from end treatment to control of the whole production process. It is mainly embodied in the following. (1) The structure of raw materials has changed. The production and use of green low-carbon energy, such as natural gas, has increased. The exploitation and utilization of biofuels and unconventional oil and gas resources has accelerated. (2) The requirement of clean and green production process has gradually improved. Petrochemical production has gradually shifted to reuse and recycling as important content. By adopting cleaner production technology and advanced energysaving emission reduction technology, the efficiency of resources and energy utilization can be improved, and pollutant emissions can be reduced. (3) The production of green petrochemical products has increased. The quality standards of refined oil are continuously improved, and the content of sulfur, olefins and benzene is further reduced. The functional, energy-saving and environment friendly new petrochemical materials and fine chemical products have become hot spots and new growth points of development. (4) The environmental protection standards have been greatly improved, and the barriers to industry entry have become higher. Additionally, the emission control of volatile organic compounds (VOCs), characteristic organic pollutants and other pollutants is becoming increasingly stringent (Su et al., 2016).

China has become the largest country for producing chemicals and the second largest country for producing petrochemicals (Manufacturing Strategic Research Team, 2015; Pan, 2016). With the industrial upgrading of the petrochemical industry, in addition to the new equipment, new technology and new catalysts, advanced manufacturing technology, information technology and management 
technology are also necessary to build a smart manufacturing system that covers the entire industry chain and conforms to petrochemical features and development requirements. At present, China's petrochemical industry has launched the research and piloting of intelligent plants. The foundation and core of intelligent plants is CPS. Through the physical space construction of embedded sensing, computing and control of information equipment, the synergistic effect of network distributed intelligent equipment is accomplished, and factory managers can easily access the production information, and implement appropriate decisions through the intelligent terminal. This can improve manufacturing efficiency and product quality, support the innovative enterprise operation model, and effectively reduce product costs and resource consumption to provide users with more transparent and personalized service.

\section{Definition and connotation of petrochem- ical CPS}

\subsection{Definition of petrochemical CPS}

CPS was first proposed by the NSF at the NSF Workshop on Cyber-physical Systems (Wang and Xie, 2011) and has attracted wide attention from academia and industry. Experts and scholars gave different definitions of CPS from different perspectives; e.g., Lee (2007) gave the definition from the perspective of the physical entity and virtual entity, and Branicky (2008) gave the definition from the perspective of embedded system development and noted that CPS is an intelligent system that integrates computing and control capabilities. The petrochemical industry is a typical representative of the process industry, and former studies (Li, 2016a; Li et al., 2015) have given the definition of a petrochemical smart factory, pointing out that CPS is the core.

Modern petrochemical plants are green, efficient, safe and sustainable factories based on the deep integration of industrialization and new generation of information technology. The goal is to achieve the excellent operation of the factory, specifically reflected in optimized allocation of resources, maximizing asset utility, optimal overall labor productivity, stable production operations, cleaner production processes, and improved employee skills.

- A petrochemical smart factory orients the entire industry chain; fuses information technology, production process technology and equipment operation technology; achieves highly horizontal, vertical and end-to-end integration; enhances the four key competencies of comprehensive perception, predictive early warning, collaborative optimization, and scientific decision making; improves the level of plant operations management in a more sophisticated and dynamic manner; and promotes the creation of new manufacturing and business mode innovations $(\mathrm{Li}$, 2016a; Li et al., 2015).

- Petrochemical CPS is the infrastructure of the petrochemical plant, which aims to build a new generation of petrochemical production environments characterized by ambient perception and ambient intelligence. Petrochemical CPS connects ubiquitous sensors, intelligent hardware, control systems, computing facilities, and information-terminals into a smart network while bringing interoperability between enterprises, employees, equipment, and services to maximize the development, integration and use of various information resources, knowledge and wisdom.

\subsection{Framework of petrochemical CPS}

Petrochemical CPS is the core of petrochemical smart factories. Combined with the CPS theory and the characteristics of petrochemical smart factories, the contents of the petrochemical CPS are summarized in Table 1.

\begin{tabular}{lc}
\begin{tabular}{l} 
Table 1 Connotation of petrochemical CPS \\
\hline Framework
\end{tabular} & Content \\
\hline $\begin{array}{l}\text { One center } \\
\text { Two cores } \\
\text { Three functions }\end{array}$ & $\begin{array}{c}\text { People-centered } \\
\text { Cyber-physical real-time monitoring and } \\
\text { automation control }\end{array}$ \\
Four technical & $\begin{array}{r}\text { Information integration, sharing and collaboration } \\
\text { Integrated simulation and global optimization }\end{array}$ \\
features & $\begin{array}{c}\text { Comprehensive situational awareness, covariance } \\
\text { of virtual and real, real-time parallel computing, } \\
\text { knowledge automation }\end{array}$ \\
Five layers & $\begin{array}{r}\text { Sensing, information network, computing, } \\
\text { policy control, application }\end{array}$ \\
\hline
\end{tabular}

\subsubsection{One center - People-centered}

The core of the CPS is based on people, which is consistent with the idea of future industrial development in Industry 4.0 (Rymaszewska et al., 2017; Zezulka et al., 2016) (the workers are freed from the implementation of routine tasks so that they can focus on innovative, value-added activities). Based on the characteristics of the petrochemical industry, this paper will summarize the construction concept of CPS from the aspects of safety, innovation and social ecology.

(1) People-oriented security management philosophy

Namely: Using various intelligent equipment and technical means, so that people can avoid dangerous environments. Since the petrochemical industry is a highrisk industry, when performing the whole process, allround, no-dead-ends, no-blind-spots real-time monitoring for jobs and places with safety risks and dangerous operations, robots and automated equipment can be used to 
perform high-risk environmental operations to avoid security incidents, and employees can use handheld devices to perform remote control to ensure safe operation (Zuehlke, 2010).

(2) Education and training of knowledge workers

The professional and technical team-based organization mode is broken, and the integrated talent team from more professional fields of engineering, computing, automation, production technology, and management is formed. Through the knowledge sharing and transfer between employees, employee knowledge integration and real-time updates are achieved to make employees more creative. To meet the changing requirements of the working environment (Li, 2016a; Zuehlke, 2010), more efficient means of training are provided for employees to enhance learning ability. The evaluation of the staff assessment is no longer limited to a single area of expertise but needs to grasp the overall production process of mutual cooperation and quantitative assessment of staff's ability to provide knowledge.

(3) Change of enterprise organization and management mode

The boundaries and scale of enterprises are broken to build a dynamic organization and value network based on petrochemical CPS; the organizational form of enterprises is forced to continue transforming in the direction of flattening, processing, flexibility, networking and decentralization ( $\mathrm{Li}$ et al., 2017b). Taking into account the petrochemical industry's characteristics of high risk, long production processes, and urge for innovation, we should apply the advantages of the Internet in the aggregation, integration and optimization of various elements of resources, take customers' demands as the center, establish cross-business process systems, give employees full rights, optimize the performance system, break through the boundaries and size of enterprises, create a creative orientation to stimulate the self-organization management mode and strengthen the resource integration and business collaboration level inside the enterprise, among enterprises, and between enterprises and users to promote sustainable development.

\subsubsection{Two cores - Data and models}

The data and model are two driving forces of industrial CPS, which are generally accepted (Cyber-physical Systems development forum of China, 2017), both of which are still applicable to petrochemical CPS.

(1) Data

There are three main sources of data for petrochemical enterprises. The first source is the whole process data of the supply chain from the procurement, manufacture, sale and distribution; the second is the full life cycle data of the factory from design to operation; the third is enterprise management-control integration data from the operating management and production management to automation control. Different from discrete manufacturing, petrochemical big data has the characteristics of large volume, various types, data processing and strong timeliness. The data contains a wealth of important information that reflects reaction rules and operating status, so the data is the soul of the petrochemical enterprises. Petrochemical CPS performs accurate, real-time data exchange among different components and systems. To collect, transmit, store, and process these data, as well as find the value of virtual data information through decision-making algorithm and machine learning, one must realize the real intelligent decision-making of petrochemical CPS.

(2) Model

There are many forms of the model used in the petrochemical industry. US Smart Process Manufacturing (SPM) (Smart Process Manufacturing Engineering Virtual Organization Steering Committee, 2009) believes that smart factories are knowledge-driven and rich models. It builds data and knowledge into useful forms and applications, builds knowledge-sharing platforms, and enables companies to gain global competitiveness. Petrochemical CPS is also model-driven, and its model library can preserve the relevant mechanism model in the production process, optimization model and parameters set when special production conditions occur, solidify the mature production management processes, expert experience, and mature manufacturing technologies into the manufacturing management system, thus supporting product manufacturing management so that manufacturing activities can achieve a higher level of technology.

Petrochemical CPS combines the data-driven and model-driven, obtains seamless access to information flow, uses data support modeling tools and decision support systems to ensure that data interpretation conforms to objective physical laws and reflects the state changes of objects, maintains parameters within controls, and enables seamless access between enterprise employees and enterprise information and knowledge processes.

\subsubsection{Three functions}

Petrochemical CPS has three functions:

(1) Real-time monitoring of cyber-physics and automation control

Petrochemical CPS transforms the new petrochemical intelligent manufacturing unit through micro-electromechanical technology, embedded technology and sensor technology. It can obtain comprehensive and detailed physical systems and information systems information through the sensor network and communication network and can be automatically aware of all the key parameters through the closed-loop operation system under the distributed control; to ensure that all parameters are within the controllable range, it must accurately characterize the 
overall system by regarding petrochemical production processes and process flow as a whole.

(2) Information integration, sharing and collaboration

The amount of data generated in the petrochemical production process is amazing, and the collection, storage, and analysis of massive data are a huge challenge to the petrochemical industry. The realization of mass data flow transmission, integration and storage is one of the important functions of petrochemical CPS, including integrating the key information in the petrochemical business subsystems, integrating plant engineering and equipment files, integrating video, mobile terminals and process data, and ensuring that information equipment and physical equipment indifferent regions, different systems and different business segments can get timely access to the required information and remote collaborative analysis.

(3) Integrated simulation and global optimization

Because in petrochemical production systems the process is complex, the parameters are many, the coupling is strong, the flexibility is poor, and the system operation efficiency is not guaranteed; it is difficult to realize an optimal control system. Compared with traditional realtime monitoring, petrochemical CPS not only monitors the physical world but also takes the physical system and information system as a whole for comprehensive analysis and simulation. Through the information collected from computing components embedded in the physical device, we can realize adaptive decomposition and adjustment for comprehensive production indicators, the whole process running indicators, process operation control indicators and control system value-set to constantly adjust the entire control system to achieve the global optimization of the system.

\subsubsection{Four technical characteristics}

Petrochemical CPS has four technical characteristics: Comprehensive situation perception, virtual reality covariance, self-organization and adaptive, and real-time parallel computing.

(1) Overall situation perception

The production status, industrial video and other information are highly concentrated and integrated to provide an intuitive factory real scene for the operation and decision-makers to ensure an accurate grasp of all information and rapid decision-making.

(2) Covariance of virtual and reality

The current state of the actual plant is constantly synchronized to the virtual plant via the sensor and the communication network in real time, while the virtual plant continues to calculate the future operating status to manage and control the actual plant operation. With the help of the industry-wide perception of the network to quickly perceive the various types of information related to the factory, seamless docking between physical manufacturing space and information space can be achieved to greatly expand the understanding of the status quo of the plant and monitoring capabilities and provide the premise for fine and intelligent control.

(3) Self-organization and self-adaptive

The knowledge of the behavior and characteristics of the petrochemical plant is solidified into various processes, business models and rules, and the applicable models are tailored to meet various production management activities to achieve integration of the operation and management in existing petrochemical production processes to achieve the overall optimization from the overall perspective.

(4) Knowledge automation (Gui et al., 2016)

The non-automated working mechanism in the traditional man-machine interface interaction is broken; human's intelligent work is extended to the control system automation to achieve knowledge-based automatic processing of the modeling, control, optimization and scheduling in petrochemical production and management; the information fusion and the interaction between the computing process and the physical process are promoted.

\subsubsection{Five layers}

Based on enterprise architecture methodology and the characteristics of the petrochemical industry, this paper divides the CPS into five levels (see Fig. 1) in order to establish the integration mechanism of petrochemical production and realize the information sharing, integrated management and fusion analysis of multiple processes. Petrochemical CPS system architecture is divided into five layers, which are (1) a perception layer to achieve petrochemical CPS information perception, data preprocessing and instruction execution; (2) a communication network layer to provide a service-quality-guaranteed communication path for a variety of equipment through cable, wireless and other forms of network transmission; (3) a computing processing layer to achieve the precise processing of perceived data, provide to the strategy control layer the knowledge through fusion and distributed computing of the big data obtained from perception layer; (4) a strategy control layer mainly serving in the process control, and according to mining knowledge obtained from the system information and computing processing layer, to amend the device and production run the system model, and control the physical equipment combined with the results of the system simulation; and (5) an application layer, including production control, supply chain management, energy management, equipment management, HSE applications, to provide open interface to support the new applications of smart petrochemical plant.

\section{Architecture of petrochemical CPS}

Since the operation of people, equipment and materials in the petrochemical plant is distributed, and the factory 


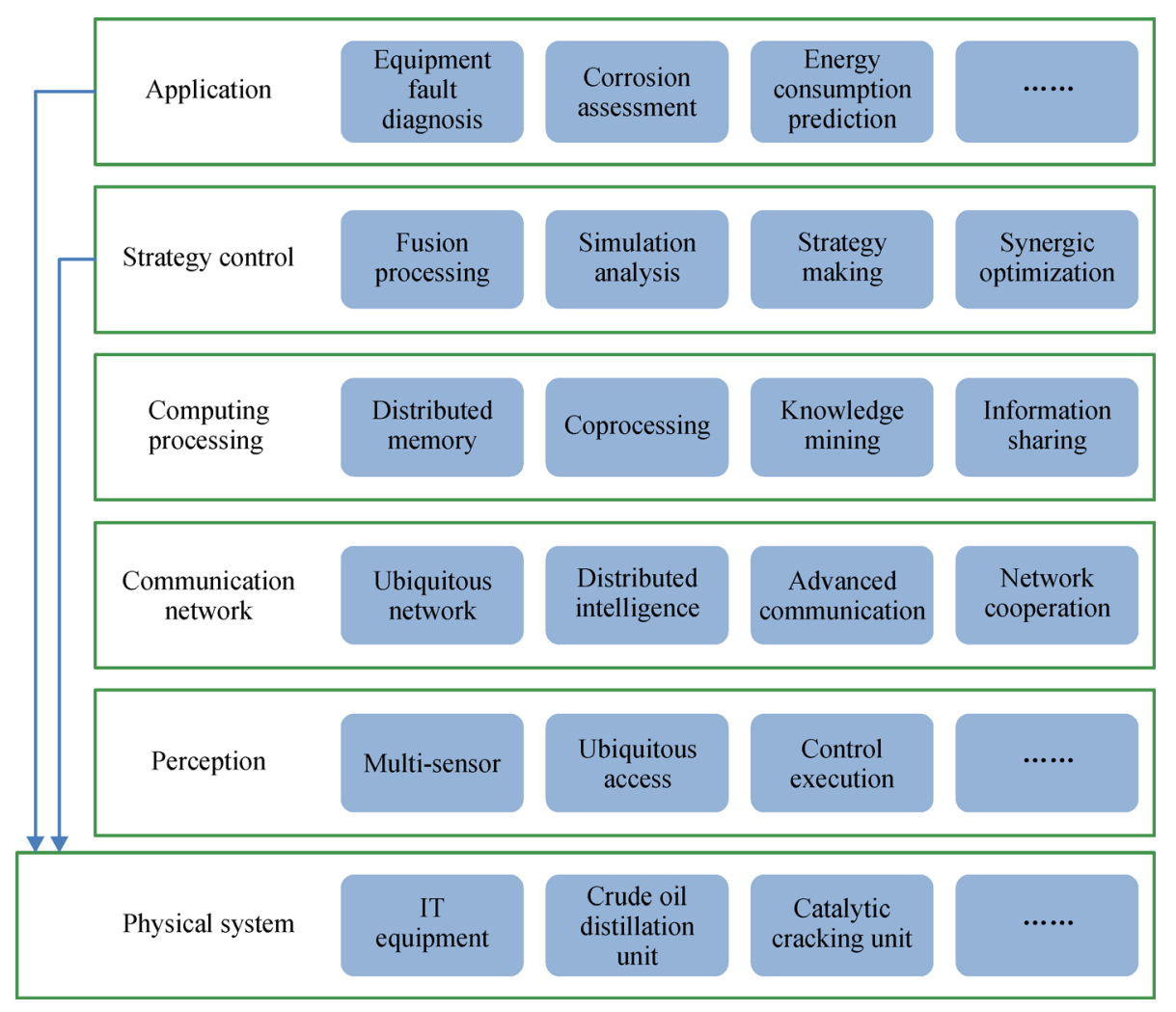

Fig. 1 Five layers of petrochemical CPS

production organization is carried out by cooperation and coordination among autonomous people, the petrochemical CPS architecture design adopts a distributed structure that is open, flexible and reliable (Liu et al., 2011; Tan and Liu, 2008). In this paper, the petrochemical CPS is divided into three systems, namely, an enterprise level, unit level and worksite level (see Fig. 2). This structure emphasizes the autonomy of each part; the overall function is carried out through coordination between each level. The biggest problems of this distributed architecture are the contradictions between the local autonomy and global optimization.

The enterprise level aims at serving the whole enterprise and solves the problem of complexity and uncertainty in design, simulation, process, production, operation, upgrade and maintenance, as well as the full life cycle of the plant, to improve the efficiency of resource allocation and realize resource optimization.

The unit level, a new type of petrochemical intelligent manufacturing unit, establishes a physical entity mapping object in the information space through physical entity virtualization of the petrochemical production site unit and dynamically tracks physical entity status and work progress, including the collection of measurement results and traceability information, to achieve high-precision simulation and optimal control of the physical unit.

The worksite level collects and obtains the device running data, tank data, equipment status data, personnel vehicle information, location data, video monitoring information, factory chemical products library information, spatial data, etc., to achieve a comprehensive perception through increasing the high-precision RFID tags, instrumentation, camera and other sensing equipment at the petrochemical site.

\section{CPS application practice in China petrochemical smart factory}

In 2013, Sinopec began construction work of smart factories in four enterprises-Yanshan Petrochemical, Maoming Petrochemical, Zhenhai Refining \& Chemical, and Jiujiang Petrochemical-according to development characteristics and the development status of the industry and Sinopec, and applied in-depth CPS to the existing petrochemical production process, achieved the deep integration and fusion of techniques, equipment operations and human resources, enhanced the four key capabilities of comprehensive awareness, prediction and early warning, collaborative optimization, and scientific decision-making, and improved the factory operation and management level in a more sophisticated and dynamic way $(\mathrm{Li}, 2016 \mathrm{a} ; \mathrm{Li}$ et al., 2015).

CPS construction of Sinopec's smart factory is divided into three levels: An enterprise level, unit level and worksite level. Among them, the enterprise-level CPS 

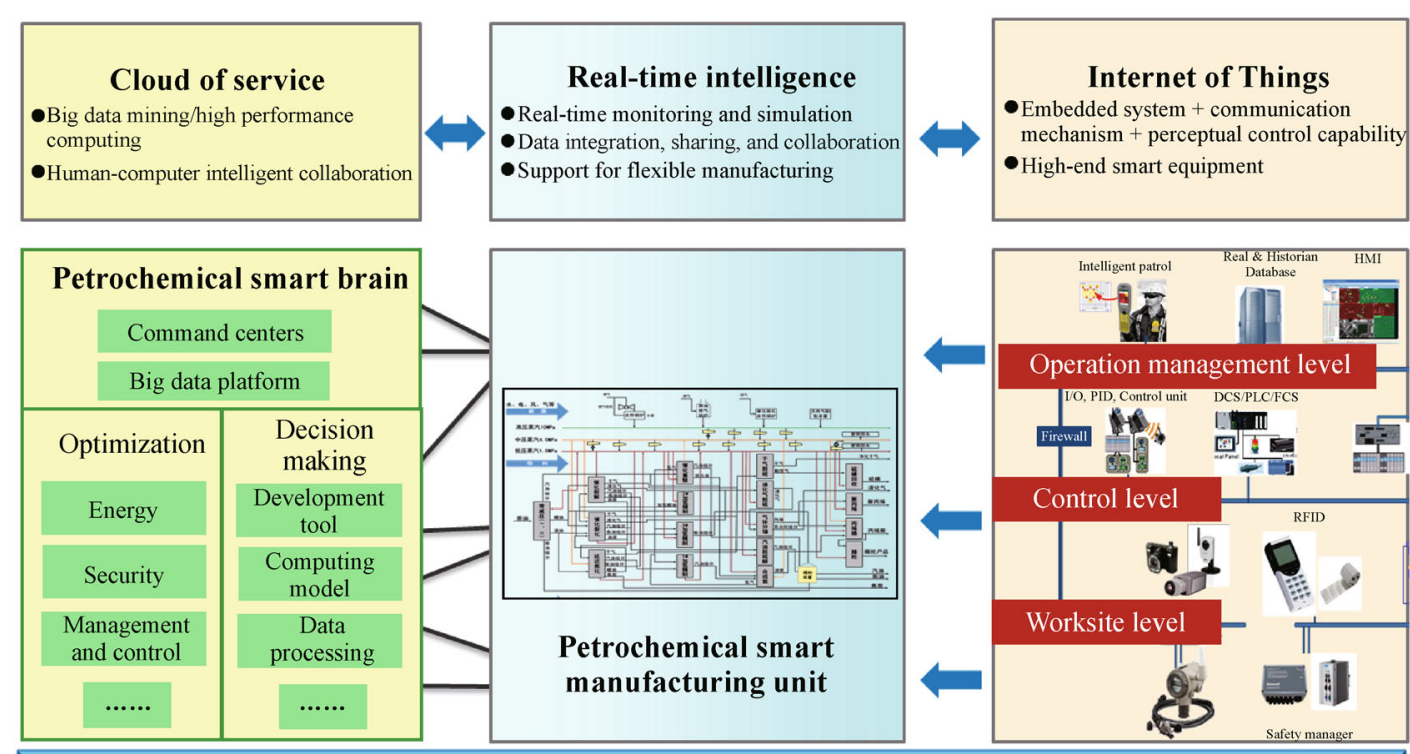

Intelligent network-based manufacturing platform

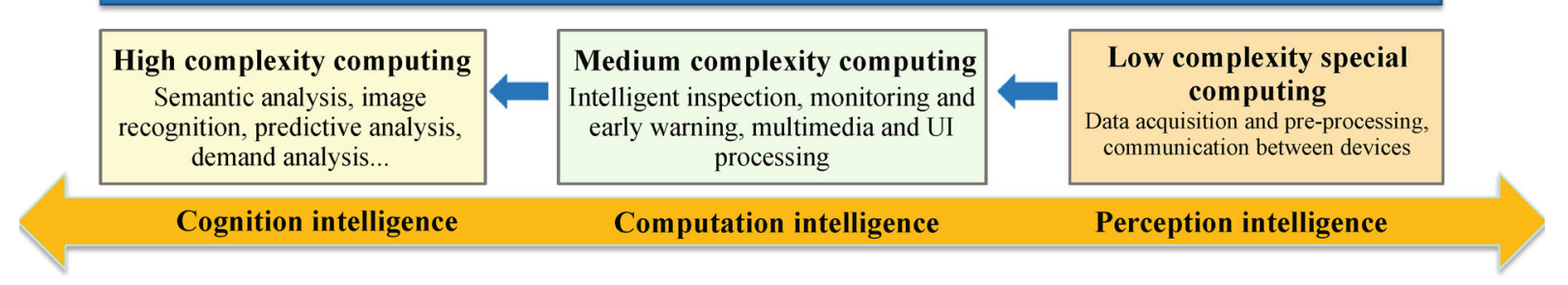

Fig. 2 Petrochemical CPS technology system

construction circles around the three main lines. The whole process integrated production control main line controls the scheduling command, energy flow management and security control. The whole process optimizing main line is in charge of the overall optimization of enterprise resources, production equipment, whole process optimization and efficiency assessment and measurement. The whole life cycle integration asset management main line is in charge of equipment risk assessment and diagnosis, equipment predictive maintenance strategy and equipment operation optimization. Unit-level CPS orients singledevice real-time closed-loop optimization, operational optimization, energy optimization and exception handling. Worksite-level CPS orients Internet of Things technology and wireless communication technology applications at worksites.

\subsection{Petrochemical smart factory-Enterprise-level CPS} application

The application of enterprise CPS in the Sinopec smart factory seeks to build a people-oriented work environment by using a variety of intelligent equipment and technical means to create a collaborative environment, to obtain information and data, to obtain collaborative knowledge of the working environment and to achieve the natural integration of the working environment.

6.1.1 Integrated production management control for the entire process

Around the main line of the entire process integrated production management control, the goal of the enterprise CPS application is to strengthen the vertical integration of the production operation and closed loop management of process control, implementation plan, scheduling, integrated operation, as well as improve the enterprise vertical management efficiency and refining level.

(1) Improving efficiency of command coordination

Through the comprehensive perception of production process, positioning, forecasting and early warning, production abnormity is rapidly captured, solutions are automatically generated, and the level of scientific decision-making is improved. Taking scheduling command as the core, the integration efficiency of planning, scheduling and operation is enhanced.

Sinopec Zhenhai Refining \& Chemical Company set up a complete scheduling system for the production scheduling of the whole company, and implemented the closedloop management of the instructions from the company 
level dispatch to the storage of the port, the dispatch of the internal operation, and the outside operation. Two level managers give work requirements, get executive feedback based on the CPS command system, and realize data synchronization and business collaboration of the dispatching instruction, the material movement, and real-time data.

(2) Realizing fine management of energy flow

Here, the goal is minimizing the energy consumption and optimizing the production capacity, optimizing the energy, improving the comprehensive monitoring of energy, medium, and analysis capabilities, and improving energy efficiency.

Sinopec Jiujiang Company and Sinopec Maoming Company apply energy online optimization technology to globally optimize the steam power system, balance the plant and local interests, give and implement feasible and optimized operation plans, and help enterprises to achieve energy savings, emissions reduction and increased efficiency. For energy management, we can increase the data collecting rate from metering instruments through CPS, visualize energy operations, realize energy supply, production, transformation, transmission, and consumption over full business process management, a real-time push optimization program, and reasonable calculation of optimization benefits. Through an energy flow balance diagram, Sinopec Jiujiang Company achieved real-time monitoring of the entire production process of input and output energy, industrial production, consumption, processing output, comprehensive energy consumption and energy loss so that managers could find what they needed the first time and perform timely adjustments to the user side as normal.

(3) Strengthening the control level of the safety and environmental protection process

In the security control link, the goal is to integrate fire protection and security platforms, improve the enterprise's ability in the process of emergency response, resource sharing and linkage command. They integrate environmental monitoring data, to achieve real-time visualization of environmental protection information, and strengthen environmental risk monitoring and analysis capabilities.

Sinopec Maoming Company has established a mechanism based on collaborative response and resource sharing. Using communication fusion and three-dimensional digital technology, they achieved collaborative command, reduced response costs and maximized emergency response efficiency. Furthermore, they performed a numerical simulation of the typical fire and the leakage accident and used visualization technology to simulate a three-dimensional simulation exercise aiming at the accident occurrence and the development process, enhancing the response ability of emergency conditions.

Sinopec Jiujiang Company has set up a map of environmental protection to monitor and control pollutant production, treatment and emissions during the process.
They achieve abnormal excessive warning, improve the efficiency of environmental monitoring, effectively control pollutant emissions, publicly display a good ecosystem of water observation tanks, and achieve real-time monitoring results at the national control point.

\subsubsection{Integration optimization for the entire process}

The application of enterprise CPS on the entire process of integrated optimization of the main line is intended to reduce the procurement cost of raw materials, coordinate the allocation of resources, and achieve efficient use of materials. Through optimization, it can reduce the cost of procurement of raw materials, achieve optimization on the four levels of planning, scheduling, installation and control, and maximize the benefit of the entire process of production.

(1) Improving the overall optimization level of enterprise resources

Taking the value-added nature of an enterprise supply chain as the starting point, the goal is to optimize the entire business process, improve the level of resource allocation and market responding speed, improve product quality and increase the enterprise's profits.

In Jiujiang and Maoming, two experimental enterprises built collaborative optimization management systems to maximize the benefits, which had features of production optimization, benefit forecast and real-time tracking. The systems can provide support for the application of the optimization model, maintenance management, and the business collaboration of production and operation plan execution, achieve full sharing of business information, efficient and orderly business collaborating, and realize dynamic adjustment of production optimization.

(2) Performing process optimization control of key equipment

According to the ideas of integrated optimization and business collaboration, the goal is to enhance the plan optimization model, scheduling model and the entire process optimization model and build the entire process optimization platform. It can realize production planning, scheduling and the device operation collaborative optimization, achieve integration sharing of data and real-time release of optimization results, and enhance the profitability of enterprises.

By using the entire process optimization platform, Sinopec Jiujiang Company has achieved planning optimization, scheduling optimization, and the synergistic application of desktop refineries. It continuously carries out the comparison and selection of crude oil purchasing and processing schemes, the optimization of the procurement of heavy naphtha and the CFB boiler operation scheme. In addition, it continuously optimizes the catalyzed diesel cutting temperature, improves the product structure, and increases high value-added products such as gasoline and aviation coal, etc. 
(3) Realizing daily evaluation and calculation of enterprise benefits

For the target of improving the operation quality and benefit monitoring, a model of daily benefit evaluation and calculation is established, which can reflect the daily monitoring and daily optimization of four levels of benefits from enterprises, plates, operations and devices. On the basis of analyzing daily benefit, combined with the optimization model, it can calculate the benefits of the next day and increase the production of high-value products, making the benefits responsibility traceable and the benefit target realizable.

The daily benefit management system of Sinopec Jinling Company, which aims at maximizing the benefits, makes full use of big data, investigates the potential of devices, and increases the production of high value-added products to achieve optimal resource allocation between the three plates of refining, chemical and joint venture and implement the global overall process optimization. It can calculate the benefit of assessment devices automatically, provide feasible data support for management decisions, and on the basis of smooth production, realize the benefit optimization and improve the level of enterprise benefits.

\subsubsection{Life-cycle integrated asset management}

Full life cycle integrated asset management system is defined as using operation, analysis, diagnosis, and maintenance of equipment to achieve "three shows" of equipment management, i.e., parameters display, performance display, laws reveal and to develop an effective equipment management strategy to ensure long-term operation of the device.

(1) Intelligently diagnose potential risks, guarantee security and stability

Establish a diagnosis and evaluation model for the key equipment and high-risk equipment, real-time analysis and diagnosis of the running status of the equipment, automatic positioning of the fault location, clear the cause of the failure and provide the corresponding processing recommendations to achieve the equipment of the predictive maintenance, so that the equipment can be safe in a longtime cycle.

Sinopec Yanshan Company has introduced a big data analysis platform for critical units, valves of fault prediction in terms of fault prediction. The platform processes approximately 300 million monitoring data points, which are collected from 216 vibration measurement points of 27 key units with a frequency of every $3-5$ seconds. Through the use of fault prediction algorithms for real-time prediction, the analysis speed has been enhanced more than 10 times. The valve-related data analysis and intelligent diagnosis, real-time analysis of valve operating status, early prediction and identifying of potential problems support the closed loop of health management of equipment. The data of vibration, temperature, pressure and flow of key equipment are obtained, and the fault diagnosis and analysis is performed to determine the cause of the fault accurately. The maintenance plan is automatically generated, thus ensuring targeted equipment maintenance.

(2) Reasonable development of maintenance strategies to extend the life-cycle

Develop the appropriate maintenance strategies for the specific equipment to carry out fault repair, preventive maintenance and predictive maintenance. Evaluate the effect, adjust the optimization, ensure that the equipment is running for long periods.

Through the system construction for equipment health and reliability management, Zhenhai Refining \& Chemical Company achieves a predictive maintenance as the core of all aspects of the entire process of equipment health factors monitoring and analysis. Realization of fault location and life prediction of key units is based on big data analysis and expert knowledge. The evaluation and analysis of the equipment maintenance strategy are realized based on the system/equipment/component failure risk evaluation, which can effectively improve the equipment maintenance and reliability management level. Within one year of project implementation and operation, they reduce $10 \%$ of the equipment failure rate, improve $1 \%$ of equipment availability, reduce $5 \%$ of equipment maintenance costs and $2 \%$ of equipment unplanned downtime.

(3) Providing scientific operational advice and optimizing operational performance

According to the results of typical equipment performance analysis, the equipment operation knowledge base and case library should be established, the operation of the equipment should be optimized, the rectification proposal should be checked to ensure that the equipment is in the best running condition range and the equipment life is extended to optimize the equipment performance. Through the integrated plant information (PI) system, equipment management (EM) system, video monitoring system, Zhenhai Refining \& Chemical Company establishes a unified device operation monitoring portal. In the threedimensional scene, it facilitates real-time view of real-time operating parameters, operating parameters trends, alarm information, design parameters, maintenance records and monitoring video, assists the equipment manager to monitor, analyzes the running status of the equipment in real time, ensures the safe operation of equipment, and provides strong support for the safe operation of equipment assets.

\subsection{Petrochemical smart factory-Unit-level CPS application}

The unit level CPS applications of petrochemical smart factory orient the production device, gradually transforming manufacturing units into intelligent manufacturing units through the technology related to CPS such as 
MEMS technology, embedded technology, sensor technology, etc. These applications have the ability to monitor and simulate the real physical system in real time and realize the real-time optimization control of process equipment.

(1) Closed-loop real-time optimization for devices

The problem of setting the stable operation device is solved by advanced process control (APC), through realtime optimization (RTO) to ensure that each set of values becomes the best process conditions and stability. The processing and product factory demand is met and quality excess is reduced.

Ethylene plants of Zhenhai Refining \& Chemical Company and Yanshan Petrochemical Industry Corporation realize the smooth operation of the production device through APC, realize the operation of clamping edges, improve the yield of the high-value products and reduce the energy consumption. Through the integrated application of RTO and APC, the goal of maximizing the economic benefits of the device is achieved. Based on the mechanism model, the planning, scheduling, optimization, and overall control of the system are realized. The system can be optimized automatically every three hours, and optimize 81 variables simultaneously. The synchronous application of RTO and APC in an ethylene plant realizes the closed-loop optimization operation with the benefit as the core in the entire process of the equipment.

(2) Black screen operation for devices

In the new mode of black screen operation, the screen does not light without alarm and the screen is highlighted when the alarm is displayed. Situations that the screen of the console darkens under a normal state of production and system automatically accurate warning under an abnormal state of production are realized. Labor production intensity is reduced, and emergency response speed and processing capacity are improved.

Yanshan Petrochemical Industry Corporation uses the black screen operation mode with a real-time focus on ethylene plant operation and maintenance stability, reduces the operator's screen time in the production of normal circumstances, and reduces labor intensity. Automatic recovery and fault location function can rapidly improve the emergency response speed and processing capacity in the case of abnormal production. Black screen time has reached four hours or even $16 \mathrm{~h}$, the operation stability rate increased by $5.11 \%$, automatic control rate increased by approximately $100 \%$, and unmanned operation preliminary appears.

(3) Energy optimization for devices

To reduce the comprehensive energy consumption of the unit and improve the efficiency of energy utilization, the online optimization of energy consumption with the change of unit production conditions is realized, and the efficiency of energy utilization is continuously improved.

Yanshan Petrochemical Industry Corporation achieved real-time monitoring of ethylene equipment's energy consumption, reduced device integration energy consumption, and improved energy efficiency, through the big data and mechanism modeling method as well as through the ethylene production and energy equipment modeling, plant process modeling, and on-line optimization of energy key parameters. Before and after the implementation, in the case where ethylene production remains stable, unit comprehensive energy consumption reduced from 594.24 $\mathrm{kg}$ of standard oil $/$ ton to $592.38 \mathrm{~kg}$ of standard oil/ton, that is, reduced by $1.87 \mathrm{~kg}$ of standard oil/ton. The relative operation before the comprehensive energy consumption of $594.24 \mathrm{~kg}$ of standard oil/ton was reduced by $0.32 \%$. An energy-saving profit of $8200 \mathrm{CNY} / \mathrm{d}$ was realized according to the price of $2 \mathrm{CNY} / \mathrm{kg}$ of oil and ethylene production of $2200 \mathrm{t} / \mathrm{d}$.

(4) Handling device exception

By using the analysis model of abnormal working conditions and taking into account the time series relations among multivariable alarms, the correlation analysis and real-time anomaly detection of multi parameter alarms in complex conditions are conducted.

Yanshan Petrochemical Corporation realized the automatic perception of abnormal conditions of an ethylene plant, automatic alarm, automatic push, automatic tracking and automatic shutdown. The problems of the relative shortage of actual combat experience of employees in case of emergency, open or shutdown were solved. The efficiency of abnormal handling of business personnel was improved, and early detection and timely accurate treatment was realized.

\subsection{Petrochemical smart factory-Worksite-level CPS application}

Application of worksite-level CPS at a petrochemical smart factory is mainly based on the Internet of Things and mobile application technology. Through the network of sensing facilities and software systems, various types of data from the worksite are connected, on-site analyzed, and then used to optimize the operations at worksites.

(1) Industrie $4 \mathrm{G}$ converged communications

Through the $4 \mathrm{G}$ wireless network, real-time and rapidly collected worksite audio and video information of anomalies, risks and accidents from mobile terminals enhance the personal on-site processing capabilities and the enterprise security control capabilities.

Sinopec Jiujiang Company takes the lead in using domestic technology to build 4G wireless communication networks to achieve a $4 \mathrm{G}$ wireless intercom and scheduling phone, "119" alarm system, administrative telephone, voice intercom between voice interoperability to achieve internal and external point to point video transfer, promote the improvement of management and scheduling efficiency, optimize the effective use of information resources, and improve the core competitiveness of enterprises. 
(2) Smart import and export logistics management

The Internet of Things and mobile technology are used to achieve orderly delivery, optimize product transport programs, improve logistics efficiency and reduce logistics costs. Models and algorithms are used to achieve the carrier online booking delivery function, optimize the parking lot resources and human resources through realtime update of parking lot information, achieve real-time tracking and control of the transport personnel and vehicle qualification, dangerous goods shipment process and other information to effectively improve the efficiency and reduce logistics risk.

Through the sale IC card, access control system, import and export logistics system (reservation called number), three-dimensional warehouse and other multi-system effective integration, Zhenhai Refining \& Chemical Company successfully opens up the supply chain business links of vehicle identification, delivery, entering plant, queuing, picking, and loading to achieve efficient coordination among the carriers' vehicles, orders, inventory, and production so that the financial posting rate increases by $50 \%$, disorder is avoided, and real-time and fine inventory management is achieved. On-site confirmation of more than $50 \mathrm{import} /$ export and loading checks, as well as operation monitoring of vehicles, were realized, which effectively promoted the safety management level of hazardous chemicals transport.

(3) Three-dimensional warehouse

The three-dimensional warehouse is used to achieve solid product automatic filling, sealing, transfer, palletizing and unmanned loading shipments and reduce labor intensity as well as to ensure first-in first-out processes, prevent the backlog of goods, and automate inventory to achieve standardized operations and avoid manual processing errors; to optimize logistics procedures, improve warehouse utilization and production efficiency, speed up cash flow, and save liquidity.

Zhenhai Refining \& Chemical Company used the application of the Internet of Things and infrared and robot technology to build the first 25000-ton, large-scale fully enclosed, fully automatic, unmanned polypropylene three-dimensional warehouse of the domestic petrochemical industry to achieve solid product packaging, automated warehouse operations management, and unmanned loading. The operating efficiency and inventory efficiency increased significantly, while the packaging damage rate dropped significantly. Warehouse daily management staff reduced by $66 \%$ compared to the flat warehouse (the flat warehouse needs 60 people, but three-dimensional warehouse only needs 10 to 20 people), and forklift operators were reduced by $50 \%$ (flat warehouse requires 32, threedimensional warehouse only requires 16). The level of inventory management is improved through the integration of ERP and MES systems to share data.

(4) Intelligent inspection

The intelligent inspection system can not only perform leak statistics and inspection route tracking but also monitor the real-time transmission of video information and voice communications.

The ethylene plant of Sinopec Yanshan Company employs the intelligent inspection system to make up for the lack of traditional inspection systems. The intelligent inspection system provides new technical support for realtime transmission and analysis of the inspection data while improving the availability of equipment, thus providing the basis for deep digging and analysis of massive inspection data in the future.

\section{Conclusions}

This article gives the definition, connotation and technical system of petrochemical CPS based on the characteristics of the petrochemical industry and the construction of intelligent plants in China. According to the three-layer structure given in the technical system, application cases of petrochemical CPS are given at the enterprise level, unit level and field level. The cases show that the application of petrochemical CPS significantly improves the levels of intelligence and scientific decision-making in petrochemical enterprises.

\section{References}

Ashibani Y, Mahmoud Q H (2017). Cyber physical systems security: Analysis, challenges and solutions. Computers \& Security, 68: 81-97

Branicky M S (2008). CPS initiative overview. In: Proceedings of the IEEE/RSJ International Conference on Robotics and Cyber-Physical Systems. Washington D.C.: IEEE

Chen Q (2017). Japan "Manufacturing + IT" integration of innovation trends. Shanghai Informatization, 2: 80-82 (in Chinese)

Cyber-physical Systems development forum of China (2017). White Paper on Cyber-physical System (in Chinese)

Gao H, Kang X W (2017). Non-fossil fuel energy development in China of 2016 and prospects for 2017. Energy of China, 33-38 (in Chinese)

Golightly D, Sharples S, Patel H, Ratchev S (2016). Manufacturing in the cloud: A human factors perspective. International Journal of Industrial Ergonomics, 55: 12-21

Gui W H, Chen X F, Yang C H (2016). Knowledge automation and its industrial application. Scientia Sinica Information, 46(8): 1016-1034 (in Chinese)

Hao Y, Helo P (2017). The role of wearable devices in meeting the needs of cloud manufacturing: A case study. Robotics and Computerintegrated Manufacturing, 45: 168-179

Hou Z X, Zou F, Lv R Q (2014). Analysis on Cyber-physical System and its application in aeronautical manufacturing industry. Acronautical Manufacturing Technology, 465(21): 47-49 (in Chinese)

Hu H, Zhao M, Ning Z B (2016). Three-body Intelligence Revolution. Beijing: China Machine Press (in Chinese)

$\mathrm{Hu} \mathrm{J} \mathrm{T}$ (2012). Unswervingly follow the road of socialism with Chinese 
characteristics and strive to build a well-off society in an all-round way. In: Proceedings of the 18th National Congress of the Communist Party of China (in Chinese)

Jezewski J, Pawlak A, Horoba K, Wrobel J, Czabanski R, Jezewski M (2016). Selected design issues of the medical Cyber-physical System for telemonitoring pregnancy at home. Microprocessors and Microsystems, 46: 35-43

Jiang F, Yang Y, Rui P L (2012). Functional characteristics and research outline of Cyber-physical System. Command Information System and Technology, 27-30 (in Chinese)

Jiang Z M (2003). Building a well-off society in an all-round way and creating a new situation of socialism with Chinese characteristics. In: Proceedings of the 16th National Congress of the Communist Party of China (in Chinese)

Kagermann H, Wolfgang W, Helbig J (2013). Recommendations for implementing the strategic initiative industrie 4.0. Industrie 4.0 Working Group

Khajenasiri I, Estebsari A, Verhelst M, Gielen G (2017). A review on Internet of Things solutions for intelligent energy control in buildings for smart city applications. Energy Procedia, 111: 770-779

Kim J, Chilamkurti N (2016). Introduction to the special section on pervasive device and communications technologies for beyond IoT and CPS. Computers \& Electrical Engineering, 52: 80-81

Lee E A (2007). Computing Foundations and Practice for CyberPhysical Systems: A Preliminary Report. Technical Report UCB/ EECS-2007-72

Lee J, Shin K G (2017). Development and use of a new task model for Cyber-physical Systems: A real-time scheduling perspective. Journal of Systems and Software, 126: 45-56

Li B, Lu R, Wang W, Choo K K R (2017a). Distributed host-based collaborative detection for false data injection attacks in smart grid Cyber-physical System. Journal of Parallel and Distributed Computing, 103: 32-41

Li D (2016a). Perspective for smart factory in petrochemical industry. Computers \& Chemical Engineering, 91: 136-148

Li D, Jiang B, Suo H (2015). Overview of smart factory studies in petrochemical industry. Computer Aided Chemical Engineering, 37: 71-76

Li J, Qiu J J, Dou K Q (2017b). Research and innovation on manufacturing management model under the background of new industrial revolution. Manufacturing Automation, 130-133 (in Chinese)

Li L (2016b). Research on Cyber-physical Systems (CPS) security technology. Automation Panorama, 58-61 (in Chinese)

Liang Y, Liu S D, Guo J H (2015). Review on the key issues of grid Cyber-physical Systems. Smart Grid, 1108-1111 (in Chinese)

Liu D F, Tian H C, Liu H H (2016). Technologies architecture and application strategies of industrial CPS. ZTE Technology Journal, 16 (Chinese)

Liu S P, Zhang J, Rao Y Q, Li P G (2011). Research on distributed workshop management and control system. China Mechanical Engineering, 12(12): 1432-1435 (in Chinese)

Lu S (2016). Touch CPS. China Information Weekly (in Chinese)

Manufacturing Strategic Research Team (2015). Manufacturing Power. Beijing: Publishing House of Electronics Industry (in Chinese) Miao W (2015). Report of the state council on information construction and promoting the integration and development of informatization and industrialization. In: Proceedings of the 15th Meeting of the Standing Committee of the Twelfth National People's Congress (in Chinese)

Ministry of Industry and Information Technology of the People's Republic of China, Ministry of Science and Technology of the People's Republic of China, Ministry of Finance of the People's Republic of China, Ministry of Commerce of the People's Republic of China, State-owned Assets Supervision and Administration Commission of the State Council (2011). Some opinions on accelerating the deep integration of informatization and industrialization (in Chinese)

Naraharisetti P K, Adhitya A, Karimi I A, Srinivasan R (2009). From PSE to PSE2-Decision support for resilient enterprises. Computers \& Chemical Engineering, 33(12): 1939-1949

Ning Z B (2016). Digitalization-speaking from the three body intelligence revolution. Retrieved from http://mp.weixin.qq.com/s/ oOuVutu8uMewE8YqedlCAQ, 2017-5-30 (in Chinese)

Pan A H (2016). The current situation of petrochemical industry faced with and the key work in 2016. In: Petrochemical Industry Development Forum (in Chinese)

Poudel S, Ni Z, Malla N (2017). Real-time cyber physical system test bed for power system security and control. International Journal of Electrical Power \& Energy Systems, 90: 124-133

Rymaszewska A, Helo P, Gunasekaran A (2017). IoT powered servitization of manufacturing-An exploratory case study. International Journal of Production Economics (in press)

Smart Process Manufacturing Engineering Virtual Organization Steering Committee (2009). Smart Process Manufacturing. Retrieved from https://smartmanufacturingcoalition.org/sites/default/files/spm__an_operations_and_technology_roadmap.pdf, 2017-5-30

Su Y C, Chen S P, Tong Y H, Fan C L, Chen W H, Wang J L, Chang J S (2016). Assessment of regional influence from a petrochemical complex by modeling and fingerprint analysis of volatile organic compounds (VOCs). Atmospheric Environment, 141: 394-407

Tan S B, Liu J C (2008). Research on multi-agent based control system for continuous rolling process. CAAI Transactions on Intelligent Systems, (2): 150-154 (in Chinese)

The Essence of Industry 4.0 - CPS(2015). http://www.sohu.com/a/ 33243187_114844, 2015-9-26 (in Chinese)

The State Council of the People's Republic of China (2015). Made-inChina 2025 (in Chinese)

Wang Z J, Xie L L (2011). Cyber-physical System: A survey. Acta Automatica Sinica, 37(10): 1157-1166 (in Chinese)

The State Council of the People's Republic of China (2016). The state council's guidance on deepening the integration of manufacturing and internet. The Central People's Government of the People's Republic of China (in Chinese)

Wang X V, Wang L, Mohammed A, Givehchi M (2017). Ubiquitous manufacturing system based on Cloud: A robotics application. Robotics and Computer-integrated Manufacturing, 45: 116-125

Wen J R, Wu M Q, Su J F (2012). Cyber-physical System. Acta Automatica Sinica, 507-517 (in Chinese)

Xu G, Zhang X T, Li M (2017). Online monitoring and control method of product quality based on embedded Cyber-physical System models. Journal of Mechanical Engineering, 1-8 (in Chinese) 
Xu H Z, Li R F, Zeng L N (2014). An algorithm of service scheduling based on automotive CPS. Computing Technology and Automation, 33(3): 79-83 (in Chinese)

Zezulka F, Marcon P, Vesely I, Sajdl O (2016). Industry 4.0An introduction in the phenomenon. IFAC-PapersOnLine, 49(25): 8 12

Zhao J H, Wen F S, Xue Y S (2010). Cyber-physical power systems: Architecture, implementation techniques and challenges. Automation of Electric Power Systems, 34(16): 1-7 (in Chinese)

Zhao J H, Wen F S, Xue Y S (2011). Modeling analysis and control research framework of cyber-physical power systems. Automation of
Electric Power Systems, 35(16): 1-8 (in Chinese)

Zhao M (2016). Digital virtual body: Depth control of the physical world. Retrieved from http://mp.weixin.qq.com/s/cHn6Xw_7IhpEtuFZVPMNow, 2017-5-30 (in Chinese)

Zhou H R (2017). The development trend of internet plus integration with manufacturing industry. Administrative Reform, 25-31 (in Chinese)

Zhou K, Yang S, Shao Z (2016). Energy Internet: The business perspective. Applied Energy, 178: 212-222

Zuehlke D (2010). SmartFactory-Towards a factory-of-things. Annual Reviews in Control, 34(1): 129-138 